\title{
FRUTO AMAZÔNICO TEM EFEITO PRÓ-CICATRICIAL EM MODELO DE FERIDA IN VITRO
}

Danieli Monteiro Pillar;Universidade Federal de Santa Maria; danielipillar@gmail.com;

Euler Esteves Ribeiro Filho; Universidade do Estado do Amazonas; eulerrfilho@gmail.com; Verônica Farina Azzolin; Universidade Federal de Santa Maria; azzolinveronica@hotmail.com; Nathália Bonotto; Universidade Federal de Santa Maria; nathaaliab23@gmail.com; Ednea Aguiar Maia-Ribeiro; Fundação Universidade da Terceira Idade; edneamaiaribeiro@gmail.com; Ivana Beatrice Mânica da Cruz; Universidade Federal de Santa Maria; ibmcruz@hotmail.com; Fernanda Barbisan; Universidade Federal de Santa Maria; fernandabarbisan@gmail.com

\section{RESUM0}

Introdução: $\mathrm{O}$ envelhecimento cutâneo, é um fenômeno fisiológico gradativo que envolve degradação do colágeno, estresse oxidativo e inflamação, esses aspectos somados ao fato de muitos idosos terem dificuldade de movimentação ou serem portadores de outras doenças como o diabetes, favorecem o aparecimento de lesões de pele de difícil cicatrização, as quais prejudicam qualidade de vida e são um problema de saúde pública. O Camu-camu (Myrciaria dúbia) é um fruto Amazônico, com alto teor de vitamina $\mathrm{C}$ e outras molécula bioativas que podem ter efeito pró-cicatricial. Objetivo: Avaliar os efeitos do Camu-camu na cicatrização em modelo in vitro de lesão de pele. Metodologia: Linhagem celular de fibroblastos (HFF-1) obtida comercialmente e cultivada em condições padrão, submetida a uma arranhadura (modelo de lesão in vitro) e após suplementada com extrato de Camu-camu, concentrações de $250 \mu \mathrm{G} / \mathrm{mL}$ e $500 \mu \mathrm{G} / \mathrm{mL}$, após 24 e 72 horas avaliou-se a produção de espécies reativas de oxigênio (EROs) via ensaio da 2,7 diclorofluoresceína diacetato e o efeito na cicatrização através da comparação das imagens microscópicas via Digimizer Image Analysis Software para avaliação da arranhadura. Resultados: Ambas as concentrações do extrato de Camu-camu, em 24 e 72 horas, atuaram na diminuição da produção de EROs, o Camu-camu induziu aumento na taxa de migração dos fibroblastos para o local da arranhadura, juntamente com a ampliação da proliferação celular, ou seja, favoreceu a cicatrização. Conclusão: $O$ efeito pró-cicatrização do Camu-Camu foi demonstrado sendo este o primeiro estudo do tipo, entretanto mais estudos precisam ser realizados para confirmação desta hipótese.

Palavras-Chave: Antioxidante; Camu-Camu; Cicatrização. 